$06.5 ; 08.2$

\title{
Влияние состава зародышевого слоя AIGaAs на формирование антифазных доменов в структурах (Al)GaAs, выращенных газофазной эпитаксией на подложках $\mathrm{Ge} / \mathrm{Si}(100)$
}

\author{
(С) А.В. Рыков ${ }^{1}$, Р.Н. Крюков ${ }^{1}$, И.В. Самарцев ${ }^{1}$, П.А. Юнин ${ }^{2}$, В.Г. Шенгуров ${ }^{1}$, А.В. Зайцев ${ }^{1}$, \\ Н.В. Байдусь ${ }^{1}$ \\ ${ }^{1}$ Научно-исследовательский фризико-технический институт Нижегородского государственного университета \\ им. Н.И. Лобачевского, Нижний Новгород, Россия \\ ${ }^{2}$ Институт ффизики микроструктур РАН, Нижний Новгород, Россия \\ E-mail: rykovsc@gmail.com
}

Поступило в Редакцию 23 декабря 2020 г.

В окончательной редакции 13 января 2021 г.

Принято к публикации 17 января 2021 г.

\begin{abstract}
Исследованы гетероструктуры на основе GaAs, выращенные методом газофазной эпитаксии из металлоорганических соединений и гидридов на виртуальных подложках $\mathrm{Ge} / \mathrm{Si}$ с использованием зародышевого слоя $\mathrm{Al}_{x} \mathrm{Ga}_{1-x} \mathrm{As}$ с различным содержанием алюминия $x$ в твердом растворе. Показано влияние $x$ на плотность и размеры антифазных доменов, выходящих на поверхность образцов, и на оптические свойства слоя GaAs. Для роста использованы подложки (100) с небольшим случайным отклонением от номинальной кристаллографической ориентации $0.7^{\circ}$ к $[110]$.
\end{abstract}

Ключевые слова: гетероэпитаксия, $\mathrm{A}_{3} \mathrm{~B}_{5}$ на кремнии, антифазные дефекты, фотолюминесценция.

DOI: 10.21883/PJTF.2021.08.50852.18670

Проблемы создания гибридных эпитаксиальных структур типа $\mathrm{A}_{3} \mathrm{~B}_{5} / \mathrm{Si}$ для создания оптоэлектронных устройств активно исследуются в последние десятилетия [1]. Одной из особенностей роста полярного полупроводника $\mathrm{GaAs}$ на неполярной подложке $\mathrm{Si}$ является образование антифазных доменов - областей одного и того же материала, но с обратным расположением подрешеток Ga и As. Границы между доменами антифазные границы (АФГ) - представляют собой пары связей $\mathrm{Ga}-\mathrm{Ga}$ и $\mathrm{As}-\mathrm{As}$, что приводит к рассеянию носителей и безызлучательной рекомбинации [2]. В большинстве случаев для роста приборных структур используют подложки с отклонением порядка $4^{\circ}$, чтобы избежать формирования АФГ [3]. Однако бо́льшая часть кремниевой индустрии рассчитана на подложки $\mathrm{Si}(100)$ без отклонения, поэтому рост и исследование приборных структур на неотклоненной подложке остаются актуальной задачей $[4,5]$. Было показано, что для получения слоев без антифазных доменов достаточно использовать подложки с небольшим отклонением $\left(\geqslant 0.5^{\circ}\right)$ [6]. Хотя отклонение от основного кристаллографического направления остается важнейшим фактором в образовании и распределении антифазных доменов, наряду с этим важны параметры роста слоев $\mathrm{A}_{3} \mathrm{~B}_{5}$ (температура роста, отношение V/III), а также конкретное состояние поверхности подложки и условия образования зародышевых слоев [7]. В настоящей работе исследуется влияние состава зародышевого слоя на формирование антифазных доменов в структурах (Al)GaAs на подложках $\mathrm{Ge} / \mathrm{Si}$ с целью снижения дефектности выращиваемых струк- тур и повышения эффективности приборов на основе $\mathrm{GaAs} / \mathrm{Ge} / \mathrm{Si}$.

Ранее нами были изготовлены светоизлучающие структуры на подложках $\mathrm{Ge} / \mathrm{Si}(100)$. Исследования показали, что в активной области одной из светодиодных структур отсутствуют антифазные домены [8]. Однако в указанной работе не было уделено должное внимание ориентации используемых подложек. С помощью метода рентгеновской дифракции выявлено, что описанные в [8] структуры выращены на подложках с разориентацией $0.7^{\circ}$ (с АФГ) и $0.2^{\circ}$ (без АФГ) к направлению, повернутому на $20^{\circ}$ по часовой стрелке от [110]. В настоящей работе для исключения неопределенности, связанной с возможным различием разориентации, все структуры выращивались на подложках, полученных путем раскалывания единой виртуальной подложки $\mathrm{Ge} / \mathrm{Si}(100)$.

Виртуальная подложка $\mathrm{Ge} / \mathrm{Si}$ изготавливалась методом осаждения из газовой фазы с использованием горячей танталовой проволоки [9]. Использовалась легированная фосфором подложка $\mathrm{Si}$ с номинальной кристаллографической ориентацией (100). По данным рентгеновской дифракции подложка имела отклонение $0.7^{\circ}$ к [110]. Сначала из сублимационного источника был выращен буферный слой $\mathrm{Si}$ при температуре подложки $700^{\circ} \mathrm{C}$. Затем при температуре подложки $325^{\circ} \mathrm{C}$ выращивался слой Ge толщиной $1.9 \mu \mathrm{m}$. Рост Ge осуществлялся из газообразного источника - германа $\mathrm{GeH}_{4}$, который разлагался в области танталовой проволоки, нагретой до $1400^{\circ} \mathrm{C}$, расположенной вблизи подложки.

Слои $\mathrm{A}_{3} \mathrm{~B}_{5}$ выращивались методом газофазной эпитаксии из металлоорганических соединений и гидридов 


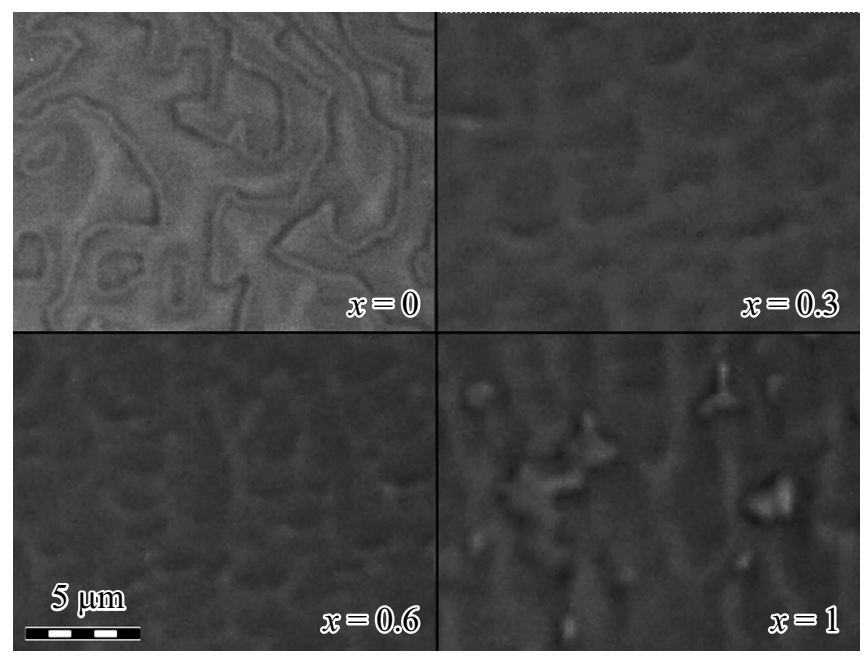

Рис. 1. Фотографии поверхности образцов $\mathrm{GaAs} / \mathrm{AlGaAs} / \mathrm{Ge} / \mathrm{Si}$ с варьируемым содержанием Al.

(MOC-гидридной эпитаксии) в установке AIX 200RF при пониженном давлении. Отношение V/III во время роста поддерживалось на уровне 80. Образцы в серии различались зародышевыми слоями $\mathrm{Al}_{x} \mathrm{Ga}_{1-x} \mathrm{As}$, где относительное содержание $\mathrm{Al}$ в твердом растворе $x$ имело значения $0,0.3,0.6$ и 1 . Подложка предварительно отжигалась в атмосфере водорода с арсином при $750^{\circ} \mathrm{C}$. Затем температура снижалась до $710^{\circ} \mathrm{C}$ и выращивалась пара слоев AlGaAs толщиной $20 \mathrm{~nm}$, разделенных $50 \mathrm{~nm}$ слоем GaAs (для образца с $x=0$ выращен сплошной слой GaAs толщиной $90 \mathrm{~nm}$ ). Затем выращивался слой GaAs:Si толщиной $1.1 \mu \mathrm{m}$.

Оптическое качество структур оценивалось методом спектроскопии фотолюминесценции (ФЛ) на установке Nanometrics RPM2000 с использованием метода картирования ФЛ, когда происходит регистрация спектров ФЛ по всей площади образцов с заданным латеральным разрешением (в настоящей работе $0.2 \mathrm{~mm}$ ). Средние значения параметров ФЛ и разброс по поверхности рассчитывались с исключением $3 \mathrm{~mm}$ от краев образцов. Для возбуждения ФЛ использовался лазер Nd:YAG с длиной волны $532 \mathrm{~nm}$ и плотностью мощности $240 \mathrm{~W} / \mathrm{cm}^{2}$. При сканировании подложки все параметры сканирования оставались одинаковыми, кроме высоты пьедестала с образцом, которая подстраивалась по максимуму интенсивности для каждого образца.

Структурное качество поверхности оценивалось методом оптической микроскопии на установке Leica DM4000 с 1500-кратным увеличением. Подробное исследование поверхности проводилось методом атомносиловой микроскопии $(\mathrm{ACM})$ на установке Solver Pro (NT-MDT). Плотность АФГ определялась по результатам ACM как отношение длины всех границ к общей площади изображения.

Данные оптической микроскопии (рис. 1) для образцов с зародышевым слоем GaAs и $\mathrm{AlAs}$ показывают наличие замкнутых линий неправильной геометрической формы, характерных для границ антифазных доменов. Для образца с AlAs $(x=1)$ размеры доменов таковы, что можно точно выделить доминантную фазу GaAs, внутри которой есть включения антифазных доменов, тогда как для образца с $\mathrm{GaAs}(x=0)$ можно заключить, что обе фазы приблизительно равносильны. При этом для $x=1$ на фоне антифазных дефектов видны также неровности поверхности, характерные и для образцов c $\mathrm{Al}_{x} \mathrm{Ga}_{1-x} \mathrm{As}(x=0.3$ и 0.6$)$. Важно, что для них на изображениях не наблюдаются АФГ.

Более подробное исследование методом АСМ выявило, что в образцах с $x=0.3$ и 0.6 также присутствуют антифазные домены, границы которых характеризуются резкими перепадами по высоте на поверхности структур (рис. 2). Плотность АФГ в этих образцах составила 0.003 и $0.019 \mu \mathrm{m}^{-1}$ для $x=0.3$ и 0.6 соответственно (по сравнению с 0.55 и $0.88 \mu \mathrm{m}^{-1}$ для образцов $\mathrm{c} x=0$ и 1 ). Следует отметить, что, несмотря на меньшие размеры
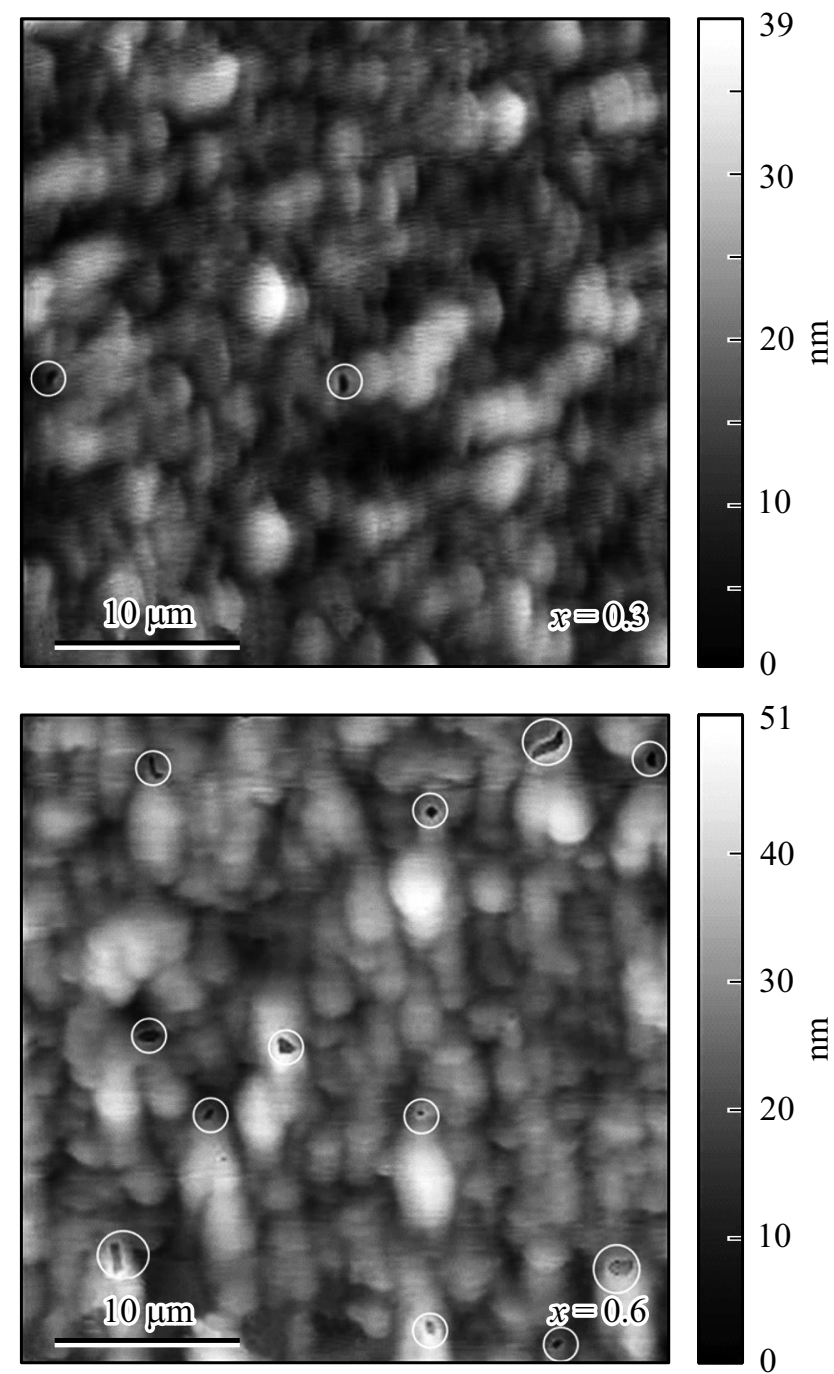

Рис. 2. АСМ-изображения поверхности образцов $\mathrm{GaAs} / \mathrm{AlGaAs} / \mathrm{Ge} / \mathrm{Si}$. Светлыми окружностями выделены антифазные домены. 


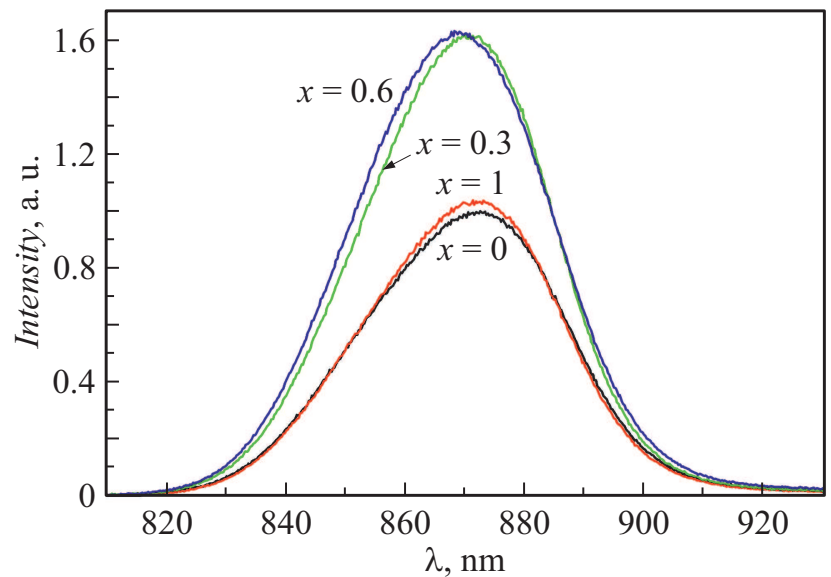

Рис. 3. Спектры ФЛ образцов GaAs/AlGaAs/Ge/Si.

доменов в образце с AlAs (средняя площадь $3.4 \mu \mathrm{m}^{2}$ ), большее число доменов и более неровные границы приводят к большей плотности АФГ, чем для образца c GaAs (средняя площадь $18.5 \mu \mathrm{m}^{2}$ ). При этом для образца с AlAs домены занимают около $35 \%$ площади поверхности, а для $\mathrm{GaAs}-40 \%$. Наименьшее количество доменов наблюдается для структуры со слоем $\mathrm{Al}_{0.3} \mathrm{Ga}_{0.7} \mathrm{As}$, их средняя площадь $\left(0.4 \mu \mathrm{m}^{2}\right)$ меньше, чем в структуре с $\mathrm{Al}_{0.6} \mathrm{Ga}_{0.4} \mathrm{As}\left(0.62 \mu \mathrm{m}^{2}\right)$. Занимаемая доменами площадь в этих образцах составила 0.05 и $0.36 \%$ соответственно.

В работе [7] рассматривается влияние ростовых параметров на соотношение скоростей роста соседних фаз (доменов) $\mathrm{A}_{3} \mathrm{~B}_{5}$. Если соотношение отличается от единицы, то при созданных условиях одна из фаз будет поглощать другую; таким образом, антифазные домены будут заращиваться, а не аннигилировать, как считалось ранее. В проведенном эксперименте АСМ-исследования образцов с $x=0.3$ и 0.6 показывают, что поверхность доменов находится на более низком уровне, чем окружающая фаза. Это свидетельствует о том, что состав выращиваемого слоя также может влиять на соотношение скоростей роста разных фаз, приводя к постепенному заращиванию антифазных доменов.

На рис. 3 показаны типичные спектры ФЛ исследуемых структур, полученные при комнатной температуре. При этом среднее значение интенсивности значительно выше для структур с $x=0.3$ и 0.6 , что свидетельствует о более высоком оптическом качестве структур вследствие уменьшения количества и размеров антифазных дефектов. Средний разброс интенсивности сигнала по поверхности образцов для $x=0$ составил $29.4 \%$, для $x=0.3-22.4 \%$, для $x=0.6-17.3 \%$, для $x=1-$ $29.7 \%$. Для образцов с меньшим количеством антифазных дефектов характерен меньший разброс интенсивности, что показывает меньшую неоднородность слоя по площади образца.

Введенные в начало структуры слои AlGaAs позволяют получить структуры с малым количеством анти- фазных доменов, выходящих на поверхность, при общей толщине структуры, не превышающей $1.2 \mu \mathrm{m}$. Эксперимент показал, что состав зародышевого слоя влияет на соотношение скоростей роста соседних доменов, что приводит к доминированию одной из фаз и ,заращиванию“ другой. В условиях эксперимента наименьшей дефектностью обладал образец с зародышевым слоем $\mathrm{Al}_{0.3} \mathrm{Ga}_{0.7}$ As. Результаты измерений ФЛ показывают значительное улучшение оптического качества структур с зародышевым слоем $\mathrm{Al}_{0.3} \mathrm{Ga}_{0.7} \mathrm{As}$ и $\mathrm{Al}_{0.6} \mathrm{Ga}_{0.4} \mathrm{As}$ по сравнению со структурами со слоями GaAs и AlAs.

\section{Финансирование работы}

Работа выполнена при поддержке Министерства науки и высшего образования РФ (проект 075-03-2020191/5), а также Российского фонда фундаментальных исследований (проект № 19-32-90184 - изготовление подложек $\mathrm{Ge} / \mathrm{Si}$ методом горячей проволоки; проект № 18-29-20016 - отработка режимов выращивания методом МОС-гидридной эпитаксии).

\section{Конфлликт интересов}

Авторы заявляют, что у них нет конфликта интересов.

\section{Список литературы}

[1] D. Liang, E. Bowers, Nature Photon., 4, 511 (2010). DOI: $10.1038 /$ nphoton. 2010.167

[2] M. Martin, T. Baron, Y. Bogumulowicz, H. Deng, K. Li, M. Tang, H. Liu, GaAs compounds heteroepitaxy on silicon for opto and nano electronic applications, in Post-transition metals (IntechOpen, 2020). DOI: 10.5772/intechopen.94609

[3] M. Liao, S. Chen, Z. Liu, Y. Wang, L. Ponnampalam, Z. Zhou, J. Wu, M. Tang, S. Shutts, Z. Liu, P.M. Smowton, S. Yu, A. Seeds, H. Liu, Photon. Res., 6, 1062 (2018). DOI: 10.1364/PRJ.6.001062

[4] N.V. Kryzhanovskaya, E.I. Moiseev, Yu.S. Polubavkina, M.V. Maximov, M.M. Kulagina, S.I. Troshkov, Yu.M. Zadiranov, A.A. Lipovskii, N.V. Baidus, A.A. Dubinov, Z.F. Krasilnik, A.V. Novikov, D.A. Pavlov, A.V. Rykov, A.A. Sushkov, D.V. Yurasov, A.E. Zhukov, Opt. Express, 25, 16754 (2017). DOI: 10.1364/OE.25.016754

[5] N. Baidus, V. Aleshkin, A. Dubinov, K. Kudryavtsev, S. Nekorkin, A. Novikov, D. Pavlov, A. Rykov, A. Sushkov, M. Shaleev, P. Yunin, D. Yurasov, Z. Krasilnik, Crystals, 8, 311 (2018). DOI: $10.3390 /$ cryst8080311

[6] Y. Bogumilowicz, J.M. Hartmann, R. Cipro, R. Alcotte, M. Martin, F. Bassani, J. Moeyaert, T. Baron, J.B. Pin, X. Bao, Z. Ye, E. Sanchez, Appl. Phys. Lett., 107, 212105 (2015). DOI: $10.1063 / 1.4935943$

[7] C. Cornet, S. Charbonnier, I. Lucci, L. Chen, A. Létoublon, A. Alvarez, K. Tavernier, T. Rohel, R. Bernard, J.-B. Rodriguez, L. Cerutti, E. Tournié, Y. Léger, M. Bahri, G. Patriarche, L. Largeau, A. Ponchet, P. Turban, N. Bertru, Phys. Rev. Mater, 4, 053401 (2020). DOI: 10.1103/PhysRevMaterials.4.053401 
[8] A.V. Rykov, M.V. Dorokhin, P.S. Vergeles, V.A. Kovalskiy, E.B. Yakimov, M.V. Ved', N.V. Baidus, A.V. Zdoroveyshchev, V.G. Shengurov, S.A. Denisov, J. Phys.: Conf. Ser., 1124, 022037 (2018). DOI: 10.1088/1742-6596/1124/2/022037

[9] S.A. Matveev, S.A. Denisov, D.V. Guseinov, V.N. Trushin, A.V. Nezhdanov, D.O. Filatov, V.G. Shengurov, J. Phys.: Conf. Ser., 541, 012026 (2014). DOI: 10.1088/1742$6596 / 541 / 1 / 012026$ 